\title{
Features of Coping Behavior of Tuberculosis Patients
}

\author{
Sukhova Elena Viktorovna* \\ Head of the Department Clinical medicine, Samara medical University, Russia \\ *Corresponding author: Sukhova Elena Viktorovna, Doctor of medical Sciences, Head of the Department Clinical medicine, Samara \\ medical University Reaviz, Russia.
}

To Cite This Article: Sukhova Elena Viktorovna. Features of Coping Behavior of Tuberculosis Patients. Am J Biomed Sci \& Res. 2019 - 4(3). AJBSR.MS.ID.000790. DOI: 10.34297/AJBSR.2019.04.000790

Received: : June 29, 2019 | Published: July 26, 2019

\begin{abstract}
Annotation
According to the results of the study of psychological and social characteristics of patients with tuberculosis, as well as the results of the survey on the targeted author's questionnaire presents the features of coping behavior of patients with tuberculosis.
\end{abstract}

Keywords: Strategies of Coping Behaviour; Psychological Characteristics of Tuberculosis Patients; Social Characteristics of Tuberculosis Patients; Directions of Psychological and Social Correction

\section{Introduction}

The bloodiest war has not claimed as many lives as tuberculosis. For many centuries it has accompanied humanity. Modern methods of genetic diagnosis revealed traces of tuberculosis in mummies of Egyptian pharaohs. Pulmonary tuberculosis is an infectious disease, the causative agent of which is Mycobacterium tuberculosis or Koch's wand. Even now, with modern advances in medicine, patients die from this disease.

Tuberculosis is a chronic infection with a long period of isolation of the pathogen, a variety of clinical manifestations, lesions of various organs and systems [1]. This is a common disease with a predominant lesion of certain systems and organs [1]. The disease is long-term, often with complications, and even now leads to disability deaths $[2,3]$. Socially disadvantaged persons are one of the risk groups of the disease. This contingent is a little disciplined, has low motivation to any systematic activity, including treatment. People who come from prison, alcohol abusers, drug addicts, unemployed, migrants are especially often ill with tuberculosis $[4,5]$. Recently, a growing number of patients who secrete strains of mycobacteria resistant to treatment. Biological cure of tuberculosis is impossible, only clinical. It requires great efforts on the part of the doctor and the patient [6-8].

Any disease causes a sick person a lot of negative emotions. Emotions can manifest themselves in external behavior. Situational emotions can "impose" certain actions on a person. Emotions drive action.
Fear is an emotion that occurs when danger is detected.

The method of coping with anxiety, fear described R. Lazarus [9]. The task of coping with negative life circumstances is to overcome difficulties, reduce their negative consequences, avoid them, endure $[10,11]$. The individual consciously and purposefully, taking into account the specific problem and his state of health, changes social behavior, applying a set of different behavioral strategies [12]. However, the available literature does not reflect the features of coping behavior of patients with pulmonary tuberculosis.

If you have TB disease in a human patient developing adverse mental reactions. These reactions affect the discipline of treatment and its effectiveness. The course of standard chemotherapy lasts a long time, the drugs have side effects. Treatment requires hospitalization, separation from the family and the usual connections, violations of the stereotype of life. We need a strong motivation for treatment, the presence of certain strong-willed qualities, internal discipline. A sick person may be disturbed by various kinds of fears and anxieties that may affect the discipline of treatment. It is necessary to take into account the fact that patients have negative experience of treatment.

The actual study of the features of the coping behavior of tuberculosis patients. The aim of the study was to study the characteristics of coping behavior of patients with tuberculosis. 


\section{Object and Methods}

A group of patients with fibrous - cavernous pulmonary tuberculosis out of 253 patients was examined there were 152 men and 101 women undergoing inpatient treatment at the Samara regional tuberculosis hospital. The patients were taken by the method of continuous sampling. The average duration of tuberculosis was $7.5 \pm 1.8$ years. Clinical methods of examination were common to confirm the diagnosis of pulmonary tuberculosis.

To study coping strategies, the questionnaire Of R. Lazarus and S. Folkman in T. L. Kryukova's adaptation was used. The Respondent is offered 50 statements on behavior in a difficult life situation. He must assess how often these behaviors are manifested in him. With the help of this questionnaire, the following coping strategies can be identified: confrontation - a fierce confrontation between a person and the situation, an aggressive response to specific life circumstances; self-control - suppression of emotions for the transition to reasonable action; the search of social support - the desire to seek the assistance of loved ones, supporters, to get rid of loneliness in a difficult moment; an escape - avoidance - avoiding the problems, the responsibility is transferred to other people; planning to solve the problem is to develop an accurate plan of the way out of the situation; distancing - the problem in the distance; a positive revaluation - the desire to see in any situation a positive side; the acceptance of responsibility - acceptance of responsibility as a given.

To identify the emotions that developed in response to the disease, the author developed a special questionnaire. A questionnaire consisting of 17 statements was developed to conduct a multivariate analysis of the causes of fear in tuberculosis patients.

The developed questionnaire allows to analyze many factors that may underlie the feeling of fear in patients with tuberculosis. It allows you to identify the fear of different nature: associated with the disease, with its treatment, with interpersonal and social interaction, the threat of loss of efficiency, the possibility of disability. The score scale of the assessment allows to reveal the value of fear of this etiology, the value of fear is measured by the patient. Statistical processing of the results allows to determine the most common causes of fear in patients with pulmonary tuberculosis.

A month after the survey, it was repeated in 30\% of respondents. There were no discrepancies in the results.

\section{Obtained Result}

The main complaints of patients were: General weakness, shortness of breath with little exercise, constant cough with a small amount of sputum, sweating at night, sleep disturbance, decreased performance. Bronchoscopic picture and histological verification data corresponded to the diagnosis of "chronic fibrosis-cavernous pulmonary tuberculosis".

Analysis of the social situation showed the following. 60,3\% of patients from rural areas had primary or incomplete secondary education, 58,4\% secondary and 8,9\% higher education. 57,8\% of the men abused alcohol and $98,7 \%$ of the smoke, a Smoking history exceeding 10 years. Among women smoked 62,4, and 38,7 $\%$ Smoking experience exceeded 10 years. 62,3 percent of the men were in prison. The disease began in prison in $40,3 \%$. Full family had $28,2 \%$, incomplete, i.e. single mother, father with children 8,1 $\%$. Single was $27,4 \%$. Lived with relatives, i.e. with brothers, sisters, members of their families, elderly parents $-36,3 \%$.

The material situation was assessed according to the following categories: lack of means of subsistence; financially dependent, i.e. income per family member was below the subsistence minimum; financially secure, i.e. having income in the form of the subsistence minimum and above. Each region has its own estimate.

It is characterized by the ratio of the subsistence budget to the average wage. The calculation is carried out for each administrative - territorial formation and is controlled by social protection services.

$55,2 \%$ of the examined patients with pulmonary tuberculosis had no means of subsistence. The disease of fibrous-cavernous pulmonary tuberculosis led to the development of a whole range of emotions. They are presented in Table 1.

\begin{tabular}{|c|c|c|}
\hline Emotions of Patients & Percentage of men & Percentage of women \\
\hline Shame for his disease by questioning and talking about it & $16,8 \pm 2,3$ & $18,3 \pm 3,1$ \\
\hline Wine in front of their friends due to the illness & $27,0 \pm 3,2$ & $40,3 \pm 2,4$ \\
\hline Confidence that others avoid and despise tuberculosis patients & $68,0 \pm 2,6$ & $80,2 \pm 1,9$ \\
\hline Dissatisfaction due to the fact that tuberculosis disease led to the restriction of contacts & $68,0 \pm 2,6$ & $80,2 \pm 1,9$ \\
\hline Feeling of fatigue from the disease, long-term treatment & $80,7 \pm 2,9$ & $60,4 \pm 2,4$ \\
\hline Fatigue from separation with close & $20,6 \pm 2,4$ & $40,7 \pm 1,7$ \\
\hline Fatigue from hospital food & $11,4 \pm 3,2$ & $36,3 \pm 1,9$ \\
\hline Fatigue from hospital environment & $20,4 \pm 1,2$ & $10,5 \pm 3,1$ \\
\hline Self-pity & $46,2 \pm 2,1$ & $61,9 \pm 1,8$ \\
\hline The sensation of his own physical weakness & $80,7 \pm 2,9$ & $60,4 \pm 2,4$ \\
\hline Fear that others will know the diagnosis and will despise and avoid & $80,7 \pm 2,9$ & $60,4 \pm 2,4$ \\
\hline
\end{tabular}




\begin{tabular}{|c|c|c|}
\hline Fear of losing one's job & $20,4 \pm 2,6$ & $27,8 \pm 2,9$ \\
\hline Fear of future uncertainty & $48,4 \pm 3,2$ & $60,4 \pm 2,6$ \\
\hline Fear of being alone due to illness & $52,4 \pm 2,5$ & $20,6 \pm 1,8$ \\
\hline Fear of the inability to physically protect yourself & $48,2 \pm 2,6$ & $20,6 \pm 1,8$ \\
\hline Fear of dying from tuberculosis & $12,3 \pm 2,6$ & $10,7 \pm 3,4$ \\
\hline The fear of speaking about the disease and & $20,5 \pm 3,1$ & $30,7 \pm 1,7$ \\
\hline Fear of long-term treatment & $38,7 \pm 2,1$ & $52,4 \pm 4,1$ \\
\hline Fear that others may see them entering the tuberculosis hospital & $72,4 \pm 2,8$ & $80,3 \pm 3,1$ \\
\hline Anger because of the isolation from society & $68,0 \pm 2,6$ & $80,2 \pm 1,9$ \\
\hline Anger due to isolation from friends & $80,3 \pm 3,2$ & $80,7 \pm 2,7$ \\
\hline Outrage and anger from lack of emotional support from family members, relatives and friends & $48,6 \pm 1,7$ & $60,8 \pm 3,2$ \\
\hline Grief due to tuberculosis & $38,8 \pm 2,5$ & $40,3 \pm 2,6$ \\
\hline The desire to obtain information about their disease and prognosis & $52,7 \pm 2,3$ & $42,9 \pm 3,1$ \\
\hline The desire to make a change in his position & $38,7 \pm 3,1$ & $52,4 \pm 2,4$ \\
\hline The desire to "get back" at the society for their disease & $25,3 \pm 2,4$ & $37,1 \pm 3,2$ \\
\hline Feeling of confidence in the successful outcome of the disease & $69,1 \pm 2,4$ & $85,7 \pm 1,8$ \\
\hline Regret that there are no more effective drugs & $60,1 \pm 3,8$ & $80,7 \pm 2,1$ \\
\hline Confidence in the competence of the doctor & $24,4 \pm 2,2$ & $35,4 \pm 1,9$ \\
\hline Confidence in using the nontraditional methods of treatment & $15,3 \pm 2,4$ & $8,9 \pm 2,3$ \\
\hline
\end{tabular}

Table 2: Fear indicators in points.

\begin{tabular}{|c|l|}
\hline Approval & Points \\
\hline I think my condition is incurable & 33,68 \\
\hline I'm afraid my relatives will turn away from me & 10,24 \\
\hline I'm afraid society doesn't need me & 21,40 \\
\hline I'm afraid I've been prescribed a lot of drugs & 20,72 \\
\hline I'm afraid the drugs have a lot of side effects & 53,90 \\
\hline I try to hide from relatives that I am sick with tuberculosis & 28,50 \\
\hline I am ashamed of my illness & 47,60 \\
\hline I'm afraid of infecting the other & 76,18 \\
\hline I'm afraid I'll be seen outside the tuberculosis hospital & 20,66 \\
\hline I'm afraid I don't have the patience to finish treatment & 27,32 \\
\hline I'm afraid I'll have trouble finding a job & 52,60 \\
\hline I'm afraid the office will find out about my condition & 22,32 \\
\hline I'm afraid to infect home & 74,54 \\
\hline I'm afraid to die & 35,64 \\
\hline I'm afraid the disease will affect my performance & 61,88 \\
\hline I can't make a career & 57,98 \\
\hline Long stay in the hospital depresses me & 71,70 \\
\hline
\end{tabular}

Thus, from the data of table 1 it becomes clear that for patients with chronic pulmonary tuberculosis the disease is a stressor. In response to the disease developed destructive emotions-grief, anger, indignation, shame, fear, guilt. The emotions revealed show how difficult the situation of the disease is. A big place is occupied by fears. Out of 253 patients, 100 were interviewed on a questionnaire aimed at studying the nature of fear. studying the etiology of fear. Respondents had to assess their own fears from 0 to 100 points. The results are presented in Table 2 .
As the table shows, the highest scores correspond to the following statements: I'm afraid to infect others; I'm afraid to infect loved ones; prolonged stay in the hospital depresses me; I'm afraid that the disease will affect my performance; I cannot make a career, i.e. the highest scores were found in social fears. Consequently, the highest sense of fear in patients with pulmonary tuberculosis is associated with the possibility of social dysfunction.

The correlation analysis of the obtained Pearson data revealed statistically significant direct and inverse correlation dependence. 
A direct significant correlation was observed between the causes of fear expressed in the statements: "I think my disease is incurable" and "I'm afraid that the drugs have many side effects" ( $r=0,394 ; \mathrm{p}$ $=0.005$ ).

"I am afraid that my relatives and friends will turn away from me" and" I am afraid to die early " $(r=0,383 ; p=0.006)$ (social and vital fear); "I am afraid that the drugs have many side effects" and "I am afraid that I will not have enough patience to finish the treatment" ( $r=0,384 ; \mathrm{p}=0.003)$. "I am afraid that the drugs have many side effects" and" prolonged hospital stay depresses me " ( $r=0,415 ; p=0,001)$. "I try to hide from loved ones that I have tuberculosis" and "I'm afraid that at work they will learn about my disease" ( $r=0,656 ; p=0,0001)$. "I am ashamed of my disease" and "I am afraid to be seen near a tuberculosis hospital" ( $\mathrm{r}=0.396 ; \mathrm{p}=$ 0.004). (social fear).

Thus, a direct correlation between the causes of fear was revealed. The inverse correlation was observed between the causes of fear "I am afraid that relatives and friends will turn away from me" and "I am afraid that I will have problems with employment" $(r=0.375 ; p=0.007)$. Logically there is a question - as patients with tuberculosis cope with a stressful situation, what ways of coping use. To study coping strategies, a survey was conducted using the questionnaire of R. Lazarus. The results are presented in Table 3.

Table 3: Coping strategies for tuberculosis patients.

\begin{tabular}{|c|c|c|}
\hline Coping strategy & Percentage of men & 74 \\
\hline search for support & 22 & Percentage of women \\
\hline planning a solution to the problem & 20 & 18 \\
\hline confrontation & 14 & 18 \\
\hline accepting responsibility & 8 & 6 \\
\hline Fourteen Eighteen & 8 & 6 \\
\hline self-checking & 6 & 4 \\
\hline
\end{tabular}

*Note: one patient can use multiple coping strategies at the same time.

Table 4: The change of behaviour of TB patients.

\begin{tabular}{|c|c|c|c|}
\hline Change in patient Behaviour & Percentage of men & Percentage of women & Significance of differences (2) \\
\hline Conversion to religion & $76,8 \pm 3,4$ & $64,7 \pm 3,6$ & $4,78^{*}$ \\
\hline Use of non-traditional treatments & $75,6 \pm 3,2$ & $34,9 \pm 1,9$ & $4,23^{*}$ \\
\hline Following the advice of other patients & $54,1 \pm 3,1$ & $31,3 \pm 2,5$ & $14,45^{*}$ \\
\hline Correct execution of medical appointments & $50,1 \pm 4,9$ & $66,2 \pm 4,7$ & $5,80^{*}$ \\
\hline Failure to comply with medical appointments & $34,2 \pm 2,5$ & $23,8 \pm 4,1$ & 3,15 \\
\hline The implementation of the rules of personal hygiene & $28,4 \pm 3,5$ & $74,4 \pm 2,3$ & $4,93^{*}$ \\
\hline
\end{tabular}

Note: * the difference is significant.

Each patient uses several coping strategies at the same time. Statistical analysis revealed no significant differences in the frequency of use of coping strategies presented by men and women. Patients with pulmonary tuberculosis are trying to cope with the disease in a different way. To study the behavior changes the author developed a special questionnaire. The results are presented in Table 4 .

Changing the behavior of sick people coping with the disease is the strategy of their coping behavior. It is significantly different in men and women. Men use religious conversion, non-traditional treatments, and advice from other patients. Women are subject to personal hygiene, medical appointments and religious practices.

\section{Discussion}

The examined group of patients with lungs was homogeneous. They all represented a real danger to others due to the fact that isolated Mycobacterium tuberculosis. $15 \%$ had multiple drug resistance. Negative emotions of patients with tuberculosis had a real reason for the appearance. $93 \%$ of men and $100 \%$ of women feel regret that there are no effective drugs. In $80 \%$ of cases, the disease led to limited contacts and social isolation. The patients themselves try to conceal their disease. $81 \%$ of women and $60 \%$ of men feel sorry for themselves. $48 \%$ of men and $60 \%$ of women experience isolation due to the disease. The desire to" take revenge " on society for their disease was revealed in 15\% of men and $9 \%$ of women.

Analyzing the features of the behavior of patients with pulmonary tuberculosis, we can distinguish the following features of coping behavior: the use of non-traditional methods of treatment; attraction to religion; infection of others. Fear of death, fear of disease, lead to the use of alternative treatments. Used in $76 \%$ of men and $35 \%$ of women. It should be explained that dry crushed cockroaches, meat of young dogs, badger fat, bear fat are used as non-traditional methods of tuberculosis treatment. If the 
patient stops the prescribed treatment and uses such "methods", he constantly infects the surrounding members of society.

Fear of death, social exclusion lead to conversion to religion. This behavior was found in $77 \%$ of men and $65 \%$ of women. Social isolation, the stigma of tuberculosis lead to ignoring the rules of hygiene and infection of others. In the questionnaire, the question was formulated as "do you observe the rules of personal hygiene." $74 \%$ of women and $28 \%$ of men answered in the affirmative. The rest do not follow the rules and thus contribute to the infection of others.

This behavior is of great social importance. Tuberculosis is an infectious disease. Only compliance with the rules of personal hygiene can prevent infection of others. And two-thirds of men with tuberculosis do not take measures to the safety of others. At the material research conducted on the scene revealed coulduse behavior of TB patients. All patients with chronic pulmonary tuberculosis need the help of a psychologist to help develop adequate behavior to cope with the disease. Fear of death, social exclusion lead to conversion to religion. This behavior was found in $77 \%$ of men and $65 \%$ of women.

Social isolation, the stigma of tuberculosis lead to ignoring the rules of hygiene and infection of others. In the questionnaire, the question was formulated as "do you observe the rules of personal hygiene." $74 \%$ of women and $28 \%$ of men answered in the affirmative. The rest do not follow the rules and thus contribute to the infection of others.

This behavior is of great social importance. Tuberculosis is an infectious disease. Only compliance with the rules of personal hygiene can prevent infection of others. And two-thirds of men with tuberculosis do not take measures to the safety of others.

At the material research conducted on the scene revealed could use behavior of TB patients. All patients with chronic pulmonary tuberculosis need the help of a psychologist to help develop adequate behavior to cope with the disease.

\section{Summary}

a. In patients with pulmonary tuberculosis revealed various negative emotions.

b. To cope with the disease is used: the use of non-traditional methods of treatment, appeal to religion, infection of healthy people. c. $\quad 77 \%$ of men and $65 \%$ of women come to religion.

d. The use of a strategy of targeted infection of healthy people by tuberculosis patients contributes to the spread of the disease among the population.

e. In the treatment of tuberculosis patients should take into account the presence of vital and social fears.

\section{References}

1. Sukhov VM, Sukhova EV (2018) Pulmonary and extrapulmonary Tuberculosis. Clinic, Diagnostics Treatment: a textbook for medical students, Samara Publishing house, Commonwealth plus pp. 138.

2. Nartova Bochaver SK (2007) "Copying Behavior" in the system of concepts of personality psychology. Psychological journal 18(5): 24-28.

3. (2008) Mechanisms of psychological protection of adolescents with the installation of "victim". Bulletin of practical psychology of education 3: 67-70.

4. Vasilyuk FE (2014) Psychology experiences. Analysis of overcoming critical situations. Publishing house of Moscow University, Moscow, Russia.

5. Semichev SB (2012) Theory of crises and prevention, The works of the Leningrad scientific, research, the psycho-neurological Institute. VM Bekhtereva (Ed) Neuroses and borderline conditions 63: 96-99.

6. Ayers TS, Sandier IN, West SG, Roosa MW (1996) A dispositional and situational assessment of children's coping: Testing alternative models of coping. Journal of personality 64(4): 923-958.

7. Carpenter BN (1992) Issues and advances in coping research, Personal coping: Theory, research and application. Praeger, Westport, Fairfield, p. 1-13.

8. Causey DL, Dubow EF (1993) Negotiating the transition to junior high school: The contributions of coping strategies and perceptions of the school environment. Prevention in Human Services 10(2): 59-81.

9. Compas BE, Forsythe CJ, Wagner BM (1988) Consistency and variability in causal attributions and coping with stress. Cognitive therapy and research. 12(3): 305-320.

10. Lazarus RS, Folkman S (1984) Stress, appraisal and coping. New York, USA.

11. Parsons A, Frydenberg E, Poole C (1996) Overachievement and coping strategies in adolescent males. British Journal of Educational Psychology 66(pt 1): 109-114.

12. Williams Paula G, Wiebe Deborah J, Smith Timothy W (1992) Copying processes as mediators of the relationship between health and health. Journal of Behavioral Medicine 15(3): 237-255. 